
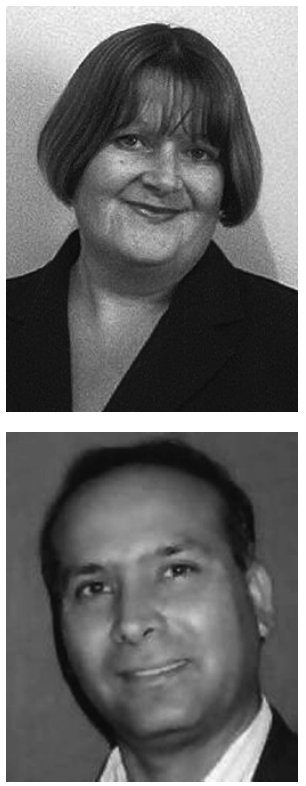

Rosemarie Begbie Cybercentricity Limited, 27 Norman Rd, Swindon, SN2 $1 \mathrm{AZ}$, UK.

Tel: $+44(0) 1793529901$; e-mail: rosebegbie@ hotmail.com

\title{
The Intranet Chaos Matrix: A conceptual framework for designing an effective knowledge management intranet
}

Received (in revised form): 15th March, 2002

\section{Rosemarie Begbie}

is the Managing Director of Cybercentricity Limited, an IT consultancy that specialises in Web/database design and usability projects. Rosemarie's interest lies in ensuring the 'usability' of databases and websites. This is because she believes that usability is an often overlooked factor that can help ensure the success of a software design project. Rosemarie has 20 years' experience working for large multinational companies in a number of project and management roles. She has a postgraduate diploma as well as a Masters in management.

\section{Farooq Chudry}

is a senior lecturer in the Business School at the University of the West of England. His main teaching responsibilities include marketing research and direct marketing. He has over 20 years' experience in the IT and empirical research field. He is a member of a supervisory team that has a number of successfully completed PhDs to its credit. He is interested in researching consumer behaviour across different cultures, an area in which he has published several articles. In addition to teaching, he has done a considerable amount of consultancy work for both private and public sector clients.

Abstract This study reviews synergies between knowledge management, ${ }^{1}$ intranet $^{2}$ usability $^{3}$ and level of control/chaos required for the organic growth of a knowledge management site. The authors developed a conceptual framework entitled 'The Intranet Chaos Matrix'.

The benefits of adopting the Intranet Chaos Matrix as a way of exploring the tension between these three factors were revealed by carrying out a case study at a multinational telecommunications organisation on their WebMap intranet site.

The WebMap online survey discovered that 70 per cent of respondents believed that the site increased their market knowledge. Only 2 per cent of respondents have had a negative experience of the intranet site. The evaluation highlighted a number of usability issues.

\section{INTRODUCTION}

This research intends to explore the complexity and dynamism of both knowledge management and intranet usability and suggests that intranet sites should not be controlled too rigidly. Indeed, a certain amount of chaos is needed to allow the site to grow organically.
Two separate and distinct schools of management have developed to explain the use and methodology of both knowledge management and intranet usability. Each of these areas has its own experts and gurus and each is certain of its own importance. After reviewing the available literature on knowledge management and usability, 
the authors came to the following conclusions:

— existing studies have not researched the synergies between intranet usability and knowledge management, nor fully explored the level of control/chaos needed to implement an effective knowledge management intranet site.

- current intranet usability studies concentrate on how well the intranet site works, while ignoring whether the site is of any practical use

- existing knowledge management intranets concentrate on communicating knowledge/information to employees in order to help them make informed business decisions. Because of the emphasis on 'content', the usability of the site may be ignored.

After reviewing the perceived knowledge gap in the literature, a conceptual framework for the design of an effective knowledge management intranet site was developed by the authors. This conceptual framework is entitled 'The Intranet Chaos Matrix', a title that reflects the balance necessary between chaos, knowledge management and intranet usability.

The benefits of adopting the Intranet Chaos Matrix as a way of exploring the tension between these three factors was revealed by carrying out a case study within a multinational

telecommunications organisation, utilising their marketing analysis and planning (MAP) intranet site, which is called WebMap.

The purpose of the WebMap intranet is to share the knowledge held by the marketing department about its market and its competitors. It is hoped that by sharing this knowledge the organisation will gain a competitive edge.

\section{LITERATURE REVIEW}

\section{Knowledge management}

The American Productivity \& Quality Center (APQC) defines knowledge management as 'the strategies and processes of identifying, capturing and leveraging knowledge' to enhance competitiveness. ${ }^{4}$ While Allee ${ }^{5}$ defines knowledge in terms of 12 qualities, Martenssen says 'knowledge is messy; it is self-organising; it seeks community; it travels on language; it is slippery; it likes looseness; it experiments; it does not grow forever; it is a social phenomenon; it evolves organically; it is a multi-modal; and it is multi-dimensional. Knowledge is of no value until it has been put into use'. 6

The authors agree with Alee's belief that rules and systems cannot be imposed. Too much rigidity regarding knowledge leads to stultification of creativity. Knowledge management thrives in a chaotic environment; try to control it too rigidly and its growth will be stunted.

Knowledge needs to be put to use achieving an organisation's goals. In a survey carried out by Chase approximately two thirds of respondents believed that costly mistakes were made due to insufficient knowledge about competitors, customers and processes. The survey also concluded that e-mail, intranets and the Internet were the most effective knowledge management tools. ${ }^{7}$

\section{The role of the Intranet in knowledge management}

Companies are using intranets as information repositories to help employees gain knowledge about the business and its competitive environment. In addition to this, intranets are used to retain that knowledge within the company when employees leave. In 
order for this 'knowledge creation' to take place the information must be presented to employees in a usable form.

Intranet technology helps organisations access knowledge resources; it also acts as a link between geographically-dispersed employees. The intranet is popular with organisations because it allows the development of a naturally expanding, flexible and easy to use knowledge management system, thus encouraging employees to take advantage of the system.

The intranet overcomes organisational hierarchies, formal communication policies, physical barriers and social groupings to make knowledge available to everyone. ${ }^{8}$

It has been said that most firms with a technology-based knowledge management system will find that the approach fails and that, although technology may be necessary for knowledge management, it appears never to be sufficient. ${ }^{9-11}$ Implementing too rigid a system may have caused this failure.

\section{Usability}

Usability is 'the effectiveness, efficiency, and satisfaction with which users can achieve tasks in a particular environment. High usability means a system is easy to learn and remember; efficient, visually pleasing and fun to use; and quick to recover from errors'. ${ }^{12}$

Forrester Research audited 20 major sites and found that only 51 per cent were compliant with simple Web usability principles such as 'is the site organised by user goals?' and 'does a search list retrievals in order of relevance?'.

The impact of bad intranet design translates directly to the bottom line of a company since any usability problems mean an immediate loss of employee productivity. Nielsen believes that the cost of poor navigation and lack of design standards is as high as US $\$ 10 \mathrm{~m}$ a year for a company with 10,000 employees, ${ }^{13}$ while good usability design commonly increases employee productivity by 25 per cent and cuts training costs by 50 per cent. ${ }^{14}$

It is recommended that when designing the page elements, the designers should look at the 20 most visited sites on the Internet and see what elements they use. If 90 per cent or more do things in a single way, then this is the de facto standard and the designer should not deviate from this standard. ${ }^{15}$

\section{Usability standards}

A standard ensures that users understand the interface elements in the design and that they know where to look for particular features. No design standard can specify completely a user interface, since the standard cannot know the specifics of the individual site. ${ }^{16}$

While standards may help reduce the learning time across sites (as the look and feel of the site will be familiar to the user), attempting to control intranets too rigidly may reduce the usability of that site. This is because each site needs to be developed according to its users' mental model.

\section{CONCEPTUAL FRAMEWORK: THE INTRANET CHAOS MATRIX}

After reviewing the literature, the authors devised the Intranet Chaos Matrix as the conceptual framework that would guide the study. The Intranet Chaos Matrix demonstrates the balance of control/chaos required for knowledge management and usability when designing an effective site.

Chaos theory explains that rapidly 


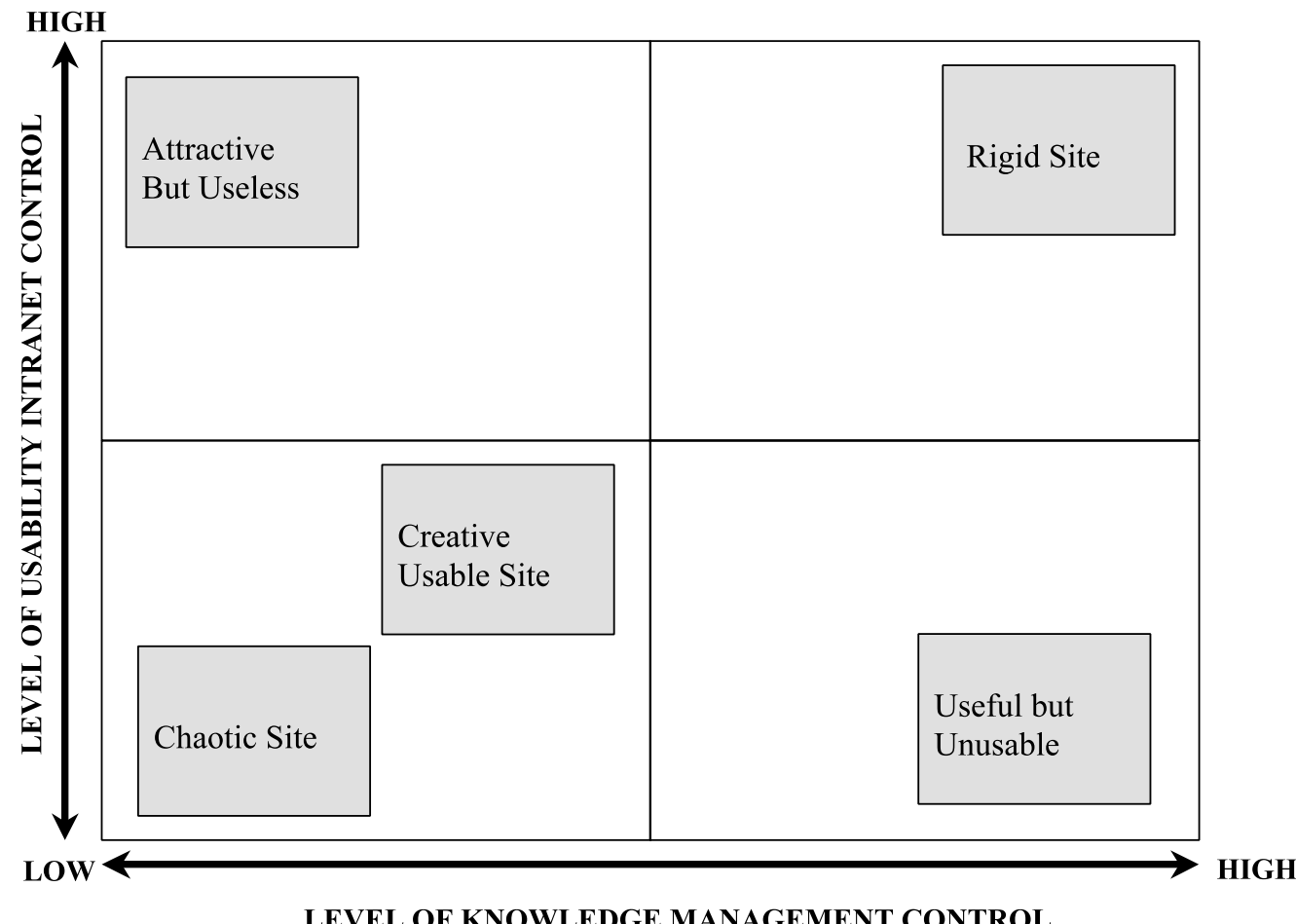

Figure 1: Intranet Chaos Matrix

changing situations require creative solutions that cannot be controlled by normal standards. ${ }^{17}$

It is the authors' intention that this study should demonstrate the importance of including both usability and knowledge management in an intranet design, and that control must not be exercised too rigidly if a creative, usable, intranet solution is to be found. The authors suggest that the fifth option from the list below (the creative usable site) would be the ideal position, as it has enough control in both disciplines to make it both interesting and usable, while accepting that in order to be a creative knowledge management site a certain amount of chaos/flexibility is necessary:

— rigid site: the level of control on this site is extremely high making it rigid and inflexible. Users will often avoid this kind of site because it does not have the fluidity or creativity to encourage knowledge sharing

- chaotic site: at the opposite end of the spectrum to the rigid site, the chaotic site has too little control, leaving it unstructured and difficult to use

- attractive but useless: this site has a high level of usability control making the navigation and layout of the site attractive to users. The level of knowledge management control, however, is low meaning that the content of the site is not aimed at helping users achieve their business goals

- useful but unusable: the high level of knowledge management control means that this site is likely to be useful in helping users achieve their business goals. The low level of usability control means, however, that 
the site may be difficult to navigate or prone to system errors

- creative usable site: in order to have a managed site a certain amount of knowledge management and usability control is required. In order to promote usable ways of creating, storing and using knowledge, control must not, however, be too strict. Although this means that a certain amount of chaos will be experienced in the development of the site, this is necessary to encourage creative knowledge solutions.

\section{RESEARCH METHODOLOGY}

\section{Research paradigm}

The dominant paradigm that the authors has followed is phenomenological. ${ }^{18}$ This is prompted by the authors' belief that ontological reality is subjective and therefore the participants' perceptions are a valuable part of the study. The usability evaluation will produce useful qualitative data.

In order to triangulate the data to provide a more balanced viewpoint the authors have included a positivistic/quantitative study in the form of an online questionnaire.

\section{Data collection methods}

\section{Sampling}

The authors used the 'judgment sampling' approach which selects participants that have experienced the phenomenon that is being studied.

The 10,210 Wireless group employees make up the population of this study, as potential users of the WebMap intranet site. The press bulletin was used to promote the online survey. The sample size is therefore the 1,200 users that read the bulletin each day. The survey remained online for two weeks and was incentivised with the offer of a bottle of champagne.

\section{Sources of data}

The two main sources or primary data in this study were 'survey data' and 'usability experimental data'. In addition to these the literature review contained secondary data.

The experimental study was carried out in a controlled environment using protocol analysis ${ }^{19}$ to identify the mental processes that evaluators used to navigate the website. The evaluators were asked to verbalise the experience, which was captured on video, this is called the 'think aloud protocol'.

The online survey was checked by a market research specialist and piloted to five users in two stages. This helped to refine the questions and to eliminate any unintentional bias. The first stage was a paper pilot survey; the second was an online pilot survey.

\section{Approach}

The approach that was taken was that of methodological triangulation which looks at the topic under investigation from different angles and vantage points. ${ }^{20}$

The research was split into three stages, as follows:

- a literature review

- an online quantitative survey

- five qualitative usability evaluation experiments.

\section{Literature review}

A review of the key literature sought to identify key themes and reveal gaps in the current debate. It also allowed the authors to place this study within a conceptual framework. They used the 
key literature to review the synergies and dynamism between knowledge management and intranet usability and also to develop 'The Intranet Chaos Matrix' as a conceptual framework to guide the study.

\section{Online survey}

A quantitative online survey was carried out on the WebMap intranet site to check whether users were satisfied with both the usability and knowledge management offered by the site. The questionnaire was available online for two weeks.

A prize draw for a bottle of champagne was offered as an incentive to complete the survey.

A five-point Likert scale was used to code and to aid analysis of the quantitative data. ${ }^{21}$ Mercator 'SNAP' software was used to file, index and categorise the text.

\section{Usability evaluation experiment}

The usability evaluation experiment was set up to identify whether users were satisfied with the usability of the WebMap intranet site, which was designed with the principles of 'The Intranet Chaos Matrix' in mind.

The authors selected five individuals both from within and without the organisation to act as usability evaluators covering a range of experience in the following three areas:

- company knowledge

- technical expertise

- experience using the marketing analysis and planning intranet site.

This cross-section covered the variety of users that the intranet site could encounter (from those with a wealth of company, intranet and technical knowledge to those with no prior knowledge of the company, intranet or technical expertise). It was important that the range of users be tested as the site is a global one - employees with differing levels of experience and expertise must use it without prior training.

According to Nielsen a usability test with five evaluators will uncover 80 per cent of the site-level usability problems plus about half of the page-level usability problems on those pages that evaluators visited during the test. ${ }^{22}$

The five usability evaluations were video-taped using two separate camcorders in order to capture the richness of data (eg participant expressions, participant 'thinking aloud', what is happening on the VDU screen, what keys are being pressed on the keyboard).

Measures of web usability are $\mathrm{e}^{23-25}$

- site-level usability: home page; information architecture; navigation and search; linking strategy; overall writing style etc

- page-level usability: specific issues related to individual pages: usefulness of headlines, links and explanations etc

- the time a task takes

- the error rate

- users' subjective satisfaction

- the frequency/persistence with which the problem occurs

- the impact of the problem if it occurs.

\section{MAIN FINDINGS AND DISCUSSION}

\section{Online survey}

The results have been separated under the headings 'knowledge management' and 'usability' to reflect the phenomena that the question is aimed at. 


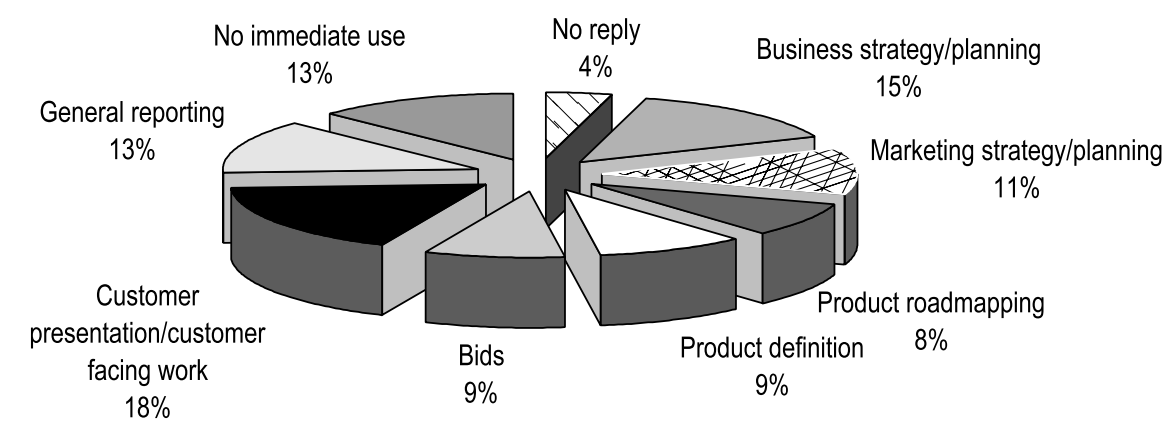

Figure 2: Primary use for information

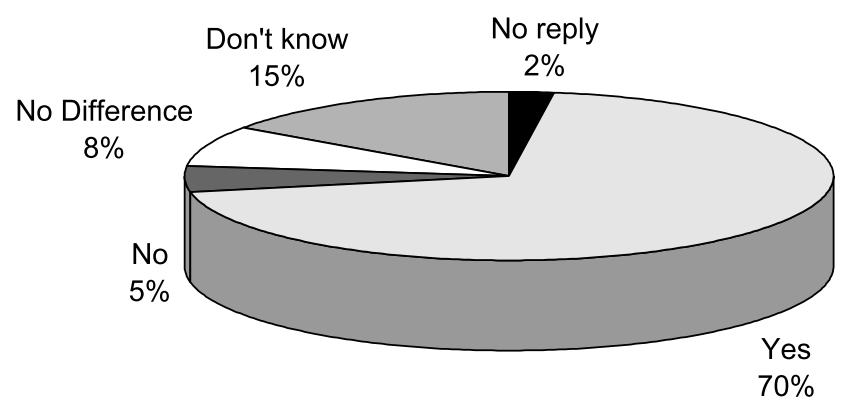

Figure 3: Increase knowledge of market

\section{Knowledge management questions}

'What is your primary use for this market information?' It has been argued that knowledge is of no value until it has been put into use, achieving an organisation's goals. ${ }^{26,27}$ As demonstrated in Figure 2, at least 70 per cent of the respondents are putting the market information to good use achieving organisational goals. Twenty-six per cent of respondents, however, answered that they either have 'no immediate use' for market information or that they use the information for 'general reporting'. It can therefore be argued that these respondents are not using the WebMap intranet site for knowledge management purposes.

'Has the information on the marketing analysis and planning website increased your knowledge of the market?' The purpose of this question was to check whether the site was achieving its objective of increasing an employee's knowledge of the market. Figure 3 illustrates that at least 70 per cent of respondents believed that the site increased their market knowledge. Only 5 per cent of respondents did not believe that the WebMap site increased their knowledge of the market. The remaining 25 per cent was compiled of: 'don't knows'; 'no difference'; 'no reply'.

'By what method do you prefer to receive the following information?' It is essential that knowledge be communicated to respondents using the method that the respondents are most receptive to; otherwise the message may be ignored. Figure 4 illustrates that the intranet was found to be the overall preferred method for receiving marketing information, with e-mail being a close second. Significantly, very few 


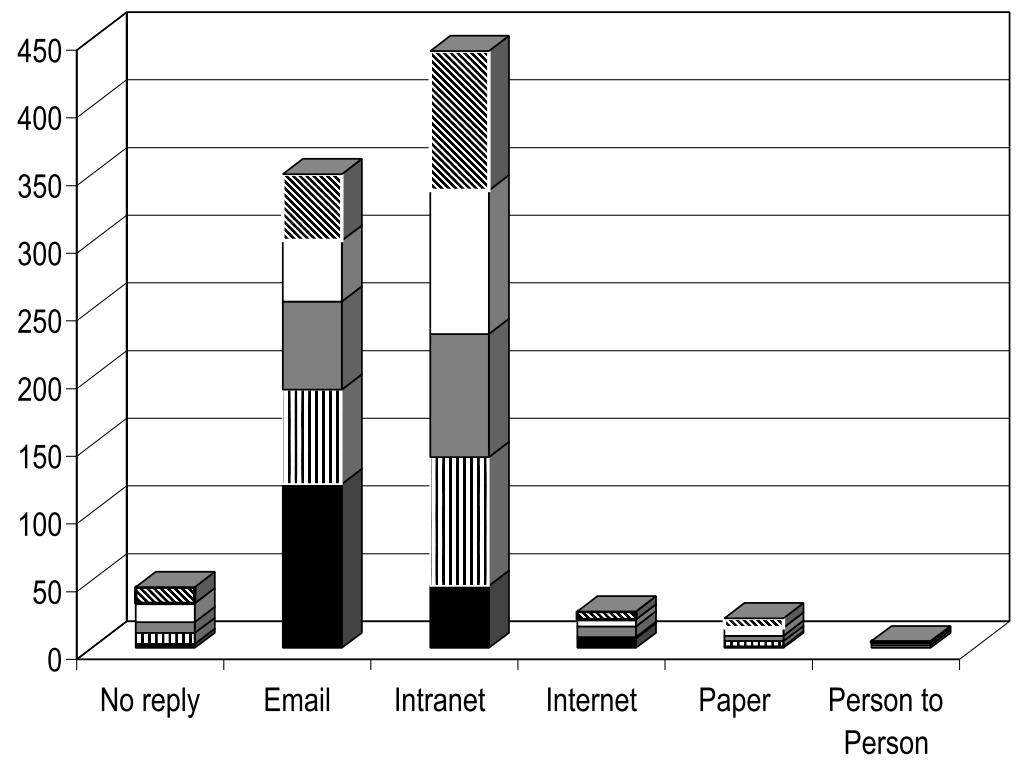

$\mathbb{\Delta}$ Market Research $\square$ Subscriber \& TAM $\square$ Competitor Info 四 Market Reports

News Bulletin

Figure 4: Preferred method for receiving information

respondents wanted to communicate in person, which is supposed to be one of the best methods of communicating knowledge. This may be due to the global nature of the organisation's Wireless group, which makes it difficult to communicate in person.

\section{Usability questions}

'In what format do you prefer to view this information?' The purpose of this question was to establish, from a usability point of view, whether the site was offering users information in the correct format. It is important to offer users their preferred format for viewing information as this has an impact on how usable the respondents believe the site to be. Figure 5 illustrates that users predominantly preferred the HTML ${ }^{28}$ format. The second most popular option was MS Office at 33 per cent, which for the purpose of this study was split into MS Office 2000 and MS Office 97. The two versions of MS Office were split to demonstrate that users of different versions need to be catered for on the intranet. The Adobe Acrobat $\mathrm{PDF}^{29}$ software was also a popular choice at 17 per cent. Each of these user preferences needs to be catered for by offering users a choice of each of the formats.

'How satisfied/dissatisfied do you feel about the following aspects of the marketing analysis and planning website: 1) Layout, 2) Ease of Use?' The purpose of this question was to establish from a usability point of view whether users were subjectively satisfied/dissatisfied with the layout and ease of use aspects of the site. Layout and ease of use are considered to be important usability factors. The aspects under consideration in this question were 'layout' and 'ease of use'. Figure 6 illustrates that approximately 55 per cent of users were either satisfied or very satisfied with the site, only 5 per cent said that they were dissatisfied. A third of respondents were neither satisfied nor dissatisfied with the layout and ease of use of the WebMap site, suggesting that there is room for improvement. This high number may 


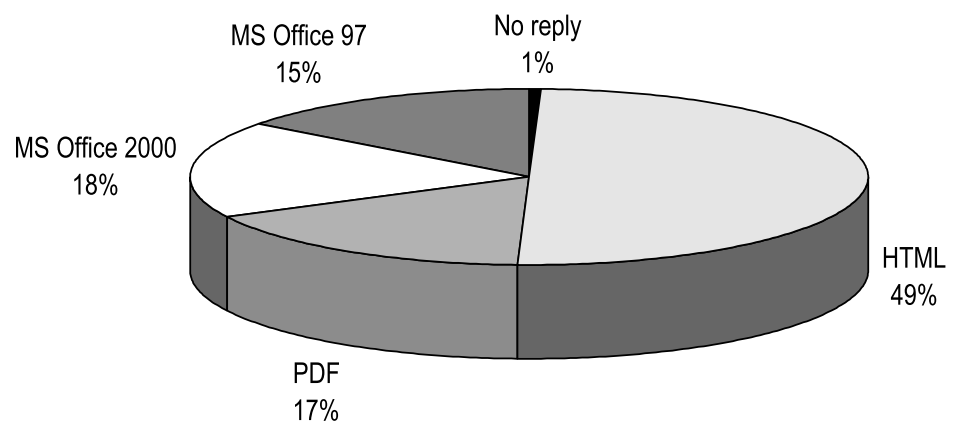

Figure 5: Preferred method of viewing information

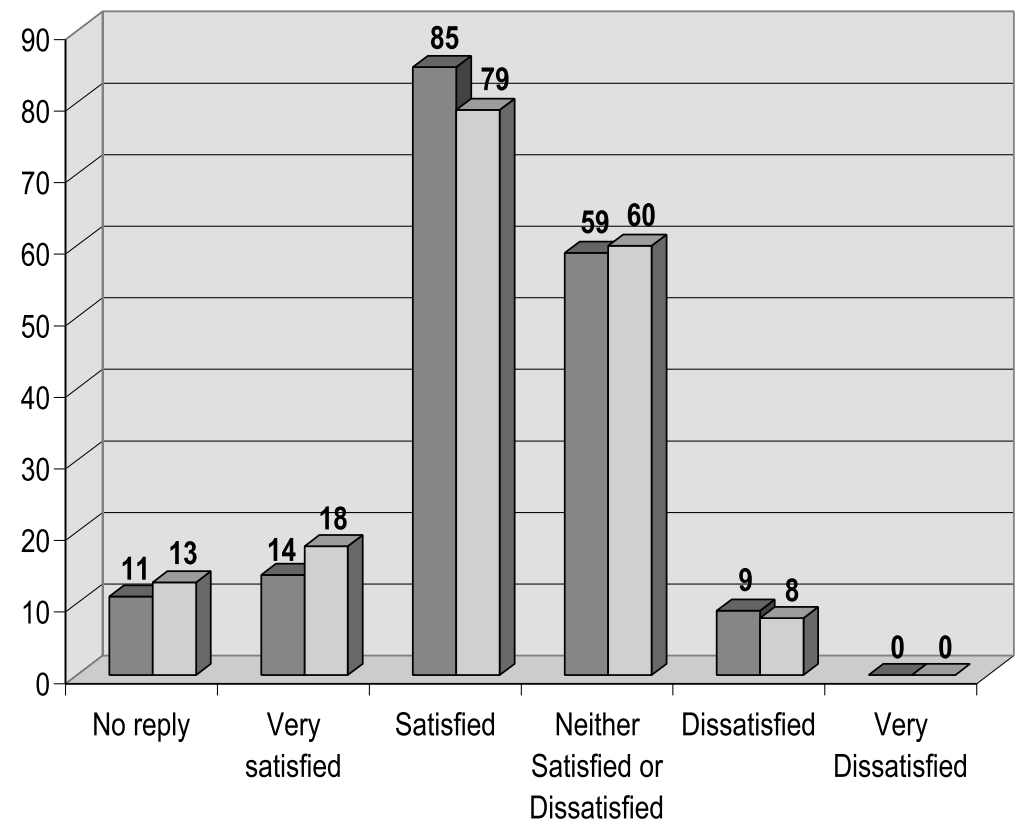

$\square$ Layout

$\square$ Ease of Use

Figure 6: Level of satisfaction with WebMap site

also be due to the fact that respondents were completing the survey for the chance to win a bottle of champagne even if they were not currently using the site.

\section{Combined knowledge management and usability questions}

'How satisfied/dissatisfied do you feel about the quality of the content within the following areas?' Previous questions about the layout of the site addressed the user's perception of the usability of the site, the user's perception of the content of the site additionally addresses whether the users are satisfied with the knowledge to be obtained from this content. Approximately 70 per cent of respondents were either satisfied or very satisfied with the quality of content for the bulletin and approximately 55 per cent were satisfied with the market reports. Respondents were, however, less satisfied with the competitor information and market research areas. Therefore 

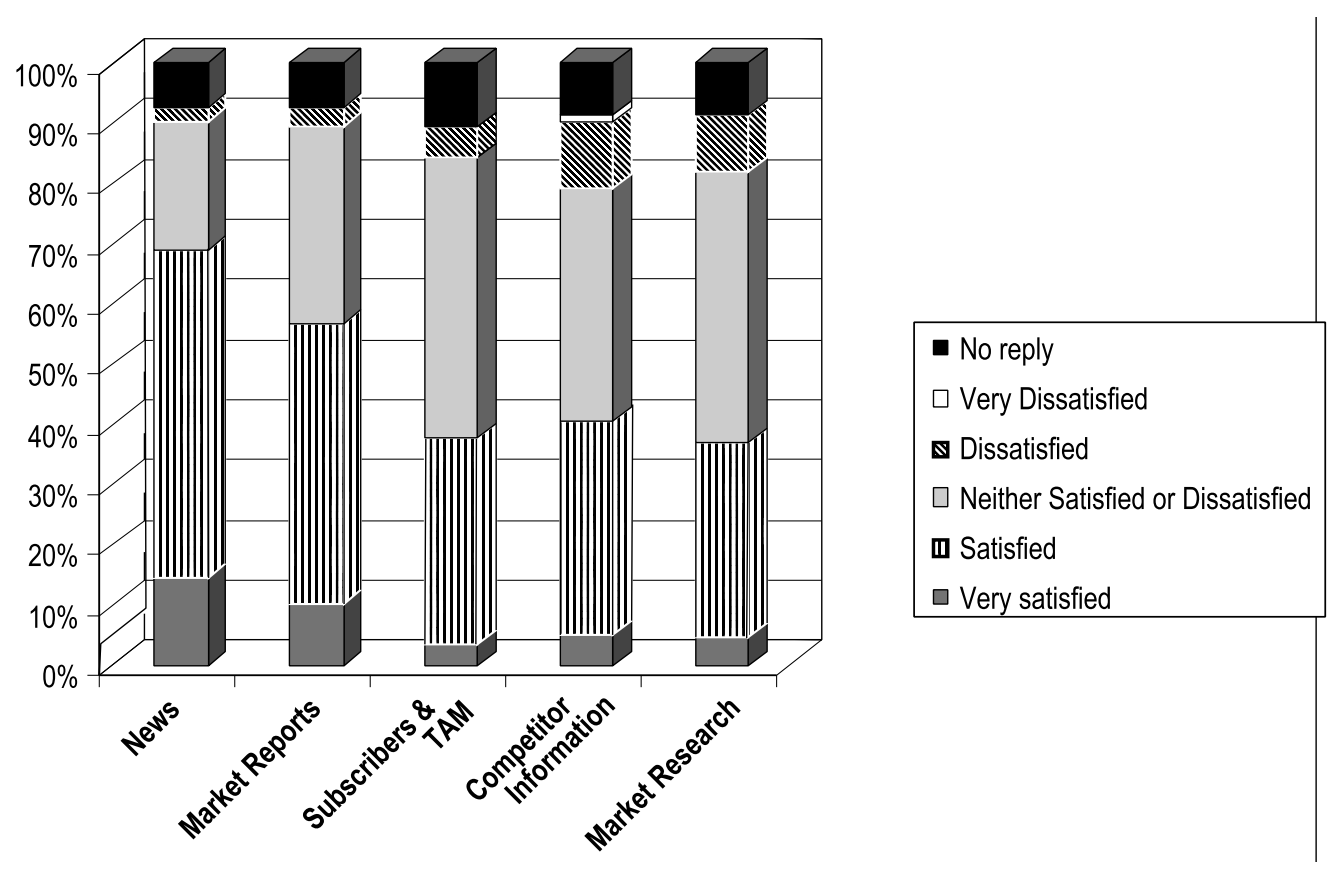

Figure 7: Level of satisfaction for quality of content

work needs to be carried out to enhance the content/information in these areas.

'Overall, how do you feel about using the marketing analysis and planning site?' The purpose of this question is to establish what the respondent's subjective experience of the WebMap intranet site is. As this question addresses the user's experience of the site overall, it applies to both usability (how the user feels) and knowledge management (content of site). The results are very positive. Figure 8 demonstrates that only 2 per cent of respondents had a negative experience of the WebMap intranet site. At least 66 per cent of users had a positive/very positive experience of the site. Although work could be done on the site to improve the 26 per cent indifferent experience of some respondents the results indicate that the majority of these respondents in this category have not even visited the WebMap site. Seventeen per cent of respondents said that they had not accessed the site in question. This appears to be due to respondents completing the survey to win a bottle of champagne.

\section{Usability evaluation experiment}

The usability evaluation experiment was set up to identify whether users were satisfied with the usability of the WebMap intranet site, which was designed with the principles of 'The Intranet Chaos Matrix' in mind. In order to test the WebMap intranet site, the evaluators followed a scenario that had been set by the researcher. The five evaluators were videoed and encouraged to 'think aloud' as they worked their way through this scenario. Each of the evaluators spent 30-60 minutes working through the scenario. The discourse from the protocol analysis was then analysed to identify common themes. These were then transcribed and collated and the issues that were identified as high frequency (in terms of the number of 


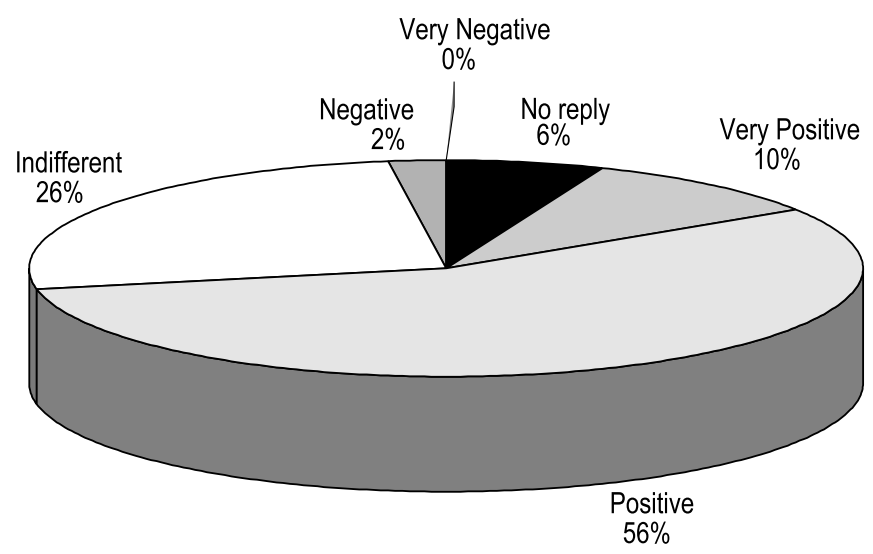

Figure 8: Site overall

times an issue was raised) and high impact (in terms of the severity of the issue), are detailed below.

\section{Navigation of the site}

'The left hand navigational bar is not grouped in a logical order'. This was a problem for 80 per cent of the participants. Although this is a classic usability problem, it was a surprise for the authors as the navigational bar had been grouped in an order that was considered logical to the MAP team. Two of the five evaluators said that they would like either an expanding menu or a tool tip to pop up when the mouse moves over the buttons on the navigation bar.

\section{Colour scheme of the site}

'The grey shading on visited links makes them difficult to read'. The colour of the hyperlink buttons text changes from white to grey to show that these buttons have been visited. This was unpopular with several of the evaluators who found the grey text too difficult to read against the coloured background of the buttons. Nielsen recommends that hyperlinks should be blue and underlined, with visited links turning purple. ${ }^{30}$ When this was suggested to users as an alternative to the coloured buttons on the navigation bar, all of the evaluators said they preferred the coloured buttons, with white text hyperlinks. This is probably because the coloured buttons are used frequently on the organisation's intranet, therefore users know how to use them.

'I would prefer a grey background, similar to that of the Knowledge Centre. The navigational bar colours are too bright against a white background'. 'I like the colour of the navigational bars and background, and don't like the grey background of the Knowledge Centre'. These comments arose when evaluators compared the WebMap intranet site to that of the organisation's Knowledge Centre. It helps illustrate that colour preferences are a very personal thing and it is not possible to please everybody. An intranet site, however, needs to allow for a number of accessibility issues, such as ensuring that text is legible for colour-blind and partially-sighted individuals.

\section{Layout of the site}

'The marketing analysis and planning title at the top of the page is too big and 
dominates the page'. 'The "make this your home page" button shouldn't be at top of screen - too pushy!' These comments show that just because something is important for the MAP team, it is not necessarily considered so by users of the site. Arguably, less emphasis should be given to promoting the site and more to allowing more space for content. The evaluators also felt that a greater emphasis could be given to show who is responsible for updating different pages on the website and highlighting the contact details for further information. This is currently displayed in a small font at the bottom of each page and is also shown in the 'Team' page.

\section{What's new section of the site}

'In order to find out what is new on the site, I need to visit it each day. I would prefer to subscribe to an email telling me what is new on the site'. Three of the evaluators believed that they should be able to subscribe to receive an e-mail telling them what is new each day. Subscription to this e-mail appears to be an important factor, as the evaluators said that they did not like receiving unsolicited e-mails such as the bulletin. The lack of control over what e-mails are received leads to the users feeling frustrated and irritable and not receptive to reading the message. This issue was also raised in the online survey. It is essential, therefore, to value the right that users have to choose whether they receive this information.

\section{Speed of the site}

Four of the evaluators commented on how fast the intranet site was at downloading files. One, however, made the following comment: ' $2-3$ second delay downloading Powerpoint slides is too slow!' This reinforces Neilsen's point that: 'Web users are getting more impatient every year. If a site doesn't provide immediate gratification they leave! ${ }^{31}$

\section{IMPLICATIONS FOR FUTURE RESEARCH}

The authors recommend the following be undertaken:

- the relationship between knowledge management, intranet usability and chaos to be further researched to gain a greater understanding of these complex, dynamic entities

- the issues highlighted by this study to be corrected on the WebMap site and this study to be updated by retesting the site in approximately six months time

- the implications of the Intranet Chaos Matrix when applied to an Internet site to be studied (in contrast to the intranet site in this research).

\section{CONCLUSIONS}

The authors designed the Intranet Chaos Matrix to deal with the complex, dynamic relationships between knowledge management, intranet usability and the level of control/chaos required for an effective site. While they suggest that the intranet is the best linking technology tool currently available for knowledge management, they recognise that not all knowledge can be codified. This is due to the nature of social discourse. It is not suggested that this discourse can be replaced, but it can be enhanced with the use of online communities and forums.

The results show that the WebMap intranet site is being put to good use for knowledge management purposes, 
achieving the organisation's goals. In the WebMap online survey it was discovered that at least 70 per cent of respondents are using the WebMap site for knowledge management purposes by putting the market information to use achieving organisational goals.

More than 70 per cent of respondents believed that the site increased their market knowledge. Only 5 per cent of respondents believed that the WebMap site did not increase their knowledge of the market.

The Intranet Chaos Matrix has provided a thorough framework for testing the effectiveness of the WebMap intranet site and has helped provide the basis for this study. As hoped for by the authors, the use of this concept has highlighted a number of knowledge management and intranet usability changes (shown in the findings section above) that need to be implemented.

The authors would therefore recommend the continued use of the Intranet Chaos Matrix as a tool to synergise the complex and dynamic relationships between knowledge management, chaos and intranet usability.

\section{References}

1 The American Productivity \& Quality Center (APQC) defines knowledge management as 'the strategies and processes of identifying, capturing and leveraging knowledge' to enhance competitiveness (Manasco, B. (1996) 'Leading firms develop knowledge strategies', Knowledge Inc, Vol. 1, No. 6, pp. 26-29; McCampbell, A. S. et al. (1999) 'Knowledge management: The new challenge for the 21st century', Journal of Knowledge Management, Vol. 3, Iss. 3).

2 An intranet is a private network used exclusively within a company or organisation. It uses Internet technology, but does not necessarily function through the Internet. Access is limited to employees or organisation members only (Vlosky et al. (2000) 'Extranets: Impacts on business practices and relationships', The Journal of Business E Industrial Marketing, Vol. 15, Iss. 6, pp. 439-440).
3 Usability is 'the effectiveness, efficiency, and satisfaction with which users can achieve tasks in a particular environment. High usability means a system is easy to learn and remember; efficient, visually pleasing and fun to use; and quick to recover from errors'. ISO Standard Definition (Ginsburg, L. and Pusedu, J. (2001) 'Usability principles that will make people want to stay awhile at your site', http://www.webtools.com/ story/site_design/tls20010314s0001).

4 Manasco (1996) and McCampbell et al. (1999) op. cit. (Ref. 1).

5 Allee, V. (1996) 'Adaptive organisations', Executive Excellence, Vol. 13, No. 3, p. 20.

6 Martenssen, M. (2000) 'A critical view of knowledge management as a management tool', Journal of Knowledge Management, Vol. 4, Iss. 3.

7 Chase, R. L (1997) 'The knowledge-based organisation: An international survey', Journal of Knowledge Management, Vol. 1, Iss. 1, pp. 38-49.

8 Meso, P. and Smith, R. (2000) 'A resourced-based view of organisational knowledge management systems', Journal of Knowledge Management, Vol. 4, Iss. 3.

9 Warren, L. (1999) 'Knowledge management: Just another office in the executive suite?', Accountancy Ireland, December.

10 Bassi, L. J. (1997) 'Harnessing the power of intellectual capital', Training And Development, Vol. 51, No. 12, pp. 25-30.

11 Martenssen (2000) op. cit.

12 ISO Standard definition, Ginsburg and Pusedu (2001) op. cit. (Ref. 3).

13 Neilsen, J. (1999a) 'The corporate information infrastructure', www.useit.com/alertbox/ 990404.html, 4th April.

14 Neilsen, J. and Coyne, K. P. (2001) 'A useful investment', www.cio.com/archive/021501/ et_pundits.html, 15th January.

15 Neilsen, J. (1999b) 'When bad elements become the standard', www.useit.com/alertbox/ 991114.html, 14th November.

16 Neilsen, J. (1999c) 'Do interface standards stifle design creativity', www.useit.com/alertbox/ 990822.html, 22nd August.

17 Nonaka, I. (1991) 'The knowledge creating company', Harvard Business Review, Vol. 6, No. 8, pp. 96-104.

18 Hussey, J. and Hussey, R. (1997) 'Business research - A practical guide for undergraduates and postgraduate students', Palgrave, Basingstoke.

19 Ibid.

20 Taylor, P. et al. (1997) 'Sociology in focus', Causway Press Ltd., Lancs.

21 Robson, C. (1993) 'Real world research', Blackwells Ltd., Oxford.

22 Neilsen, J. (1998) 'Cost of user testing a web site', www.useit.com/alertbox/980503.html, 3rd May.

23 Neilsen and Coyne (2001) op. cit.

24 Cunliffe, D. (2000) 'Developing usable websites - A review and model', Internet Research: 
Electronic Networking Applications and Policy, Vol. 10, Iss. 4.

25 Neilsen (1998) op. cit.

26 Allee (1996) op. cit.

27 Martenssen (2000) op. cit.

28 Hypertext Mark-Up Language (HTML) is the programming language used to develop most Web pages.
29 PDF $=$ Portable Document Format. Source: BABEL: Glossary of computer-oriented abbreviations and acronyms.

30 Nielsen (1999b) op. cit.

31 Neilsen, J. (1999d) 'Usability as barrier to entry', www.useit.com/alertbox/991128.html, 28th November. 